\title{
THE EFFECT OF DIGITALIS ON THE VENOUS PRESSURE
}

\author{
BY \\ PAUL WOOD AND JOHN PAULETT
}

\begin{abstract}
From the Department of Medicine, Postgraduate Medical School of London, and the Institute of Cardiology, National Heart Hospital
\end{abstract}

Received December 8, 1948

The action of digitalis on the circulation in man is not yet clearly understood. There can be no doubt that it benefits most patients with congestive heart failure, but beyond this there is no certainty.

McKenzie (1905) believed that its value was greatest in cases of congestive heart failure with auricular fibrillation and could then be attributed to slowing of the ventricular rate; Lewis (1937) agreed, maintaining that improvement was infrequent in patients with normal rhythm, because slowing of the heart rate was often inconspicuous. Dock and Tainter (1930) and Katz et al. (1938) suggested that digitalis might act primarily by constricting the hepatic vein, a throttle mechanism that was demonstrated in anæsthetized dogs; they claimed that the venous pressure was lowered by means of a bloodless venesection, blood being dammed back in the liver and portal system. Such a theory harmonized with other findings, e.g. digitalis reduced the cardiac output of normal dogs (Harrison and Leonard, 1926) and decreased the size of the heart in normal human beings (Stewart et al., 1938). In 1940, however, one of us was able to show that digitalis lowered the venous pressure in 90 per cent of cases of heart failure with normal rhythm, and that this was due neither to slowing of the heart rate nor to any hepatic vein throttle mechanism; for the venous pressiure fell as sharply when cardiac slowing was prevented, and the liver and spleen shrank simultaneously (Wood, 1940). More recently, McMichael and Sharpey-Schafer (1944),showed that mechanical lowering of the right auricular pressure by means of cuffs on the thighs produced effects on the cardiac output in man similar to those resulting from digitalis: in cases of congestive heart failure the right auricular pressure fell and the cardiac output rose; in normal subjects the right auricular pressure fell and the cardiac output fell. They suggested that digitalis might have a primary action in lower- ing venous pressure to which the other effects were subsidiary: The authors admitted that the venous pressure was lowered but slightly in normal subjects, and conspicuously only when the initial level was high; but they attributed this to a logarithmic effect.

The object of the present investigation was to discover what action digitalis might have on the venous pressure when it was elevated from causes other than congestive heart failure.

\section{MeTHOD UsED}

A consecutive series of twelve cases, in which the jugular venous pressure was raised clinically without any real evidence of congestive heart failure, was studied. The nature of the material is shown in Table I. The raised venous pressure was attributed to a hyperkinetic circulatory state in the cases of anæmia and thyrotoxicosis, and to an increased blood volume in the cases of acute nephritis and artificial hydræmia. Hydræmia was induced by means of sodium chloride $10 \mathrm{~g}$., water $10-12$ pints, and D.O.C.A. (desoxy-cortico-sterone acetate) 25-50 mg. daily for 7 to 14 days.

All observations were made with the subject lying more or less horizontal, the head being supported on one or two pillows. The antecubital venous pressure was measured directly as described in a previous paper (Wood, 1940). The right auricular pressure was measured by means of a No. 8,9 , or 10 nylon cardiac catheter and a saline manometer, as described by McMichael and Sharpey-Schafer (1944); only mean pressures can be recorded by this method. The cardiac output was estimated by means of Fick's formula, the arteriovenous oxygen difference being obtained by analysing arterial and right auricular blood samples in a modified Haldane blood gas apparatus, and the oxygen consumption 


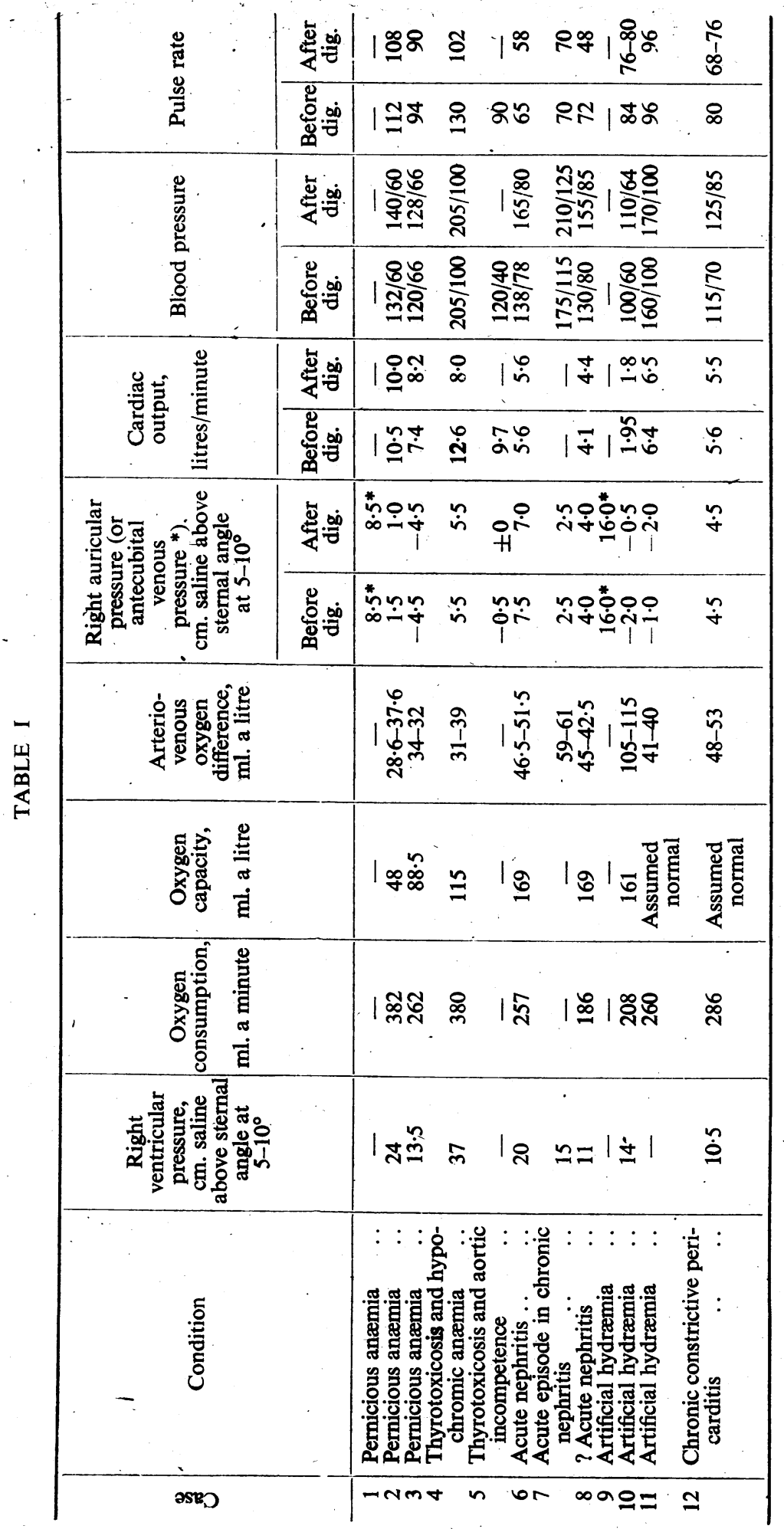


by means of a Benedict-Roth spirometer. In some cases the arterial blood was assumed to be 95 per cent saturated with oxygen. The oxygen capacity was either estimated directly by the ferricyanide method or calculated from the hæmoglobin value, results approximating closely when both methods were employed. The catheter was passed without X-ray control: to make certain the tip was in the right auricle, the right ventricle was always entered, and the catheter was then withdrawn slowly until the pressure suddenly fell and conspicuous pulsation ceased.

\section{RESULTS}

Congestive Heart Failure. In four controls with clinical congestive heart failure, mostly hypertensives, the venous or right auricular pressure fell sharply and considerably within half an hour of giving $1.5 \mathrm{mg}$. of digoxin intravenously, whether initial readings were high or relatively low (Fig. 1). At the same time the cardiac output rose, the pulse usually slowed, and the blood pressure rose (Fig. 2). These cases illustrated the well-known response of heart failure to digitalis and proved that the digoxin was potent and that the dose of $1.5 \mathrm{mg}$. was sufficient.

Anamia. There were three cases of severe pernicious anæmia: in all the jugular venous pressures were raised as judged clinically. The cardiac output was 10-14 litres a minute in one of them, 7 litres a minute in another, and was not measured in the third. Intravenous digoxin had no effect on the venous or right auricular pressures and did not alter the cardiac output; the blood pressure, however, rose (Fig. 3).

Thyrotoxicosis. There were two cases of thyrotoxicosis in which the jugular venous pressures were raised as judged clinically: one was complicated by moderate hypochromic anæmia, the other by atherosclerotic aortic incompetence. The cardiac output was 12 litres a minute in the first, 9.6 in the second. Intravenous digoxin had no effect on the right auricular pressure in either; the cardiac output fell appreciably in one of them, but this could be attributed to slowing of the pulse rate (Fig. 4).

Acute Nephritis. There was one case of classical acute nephritis, one of chronic nephritis with an acute flare-up, and one in which the diagnosis was

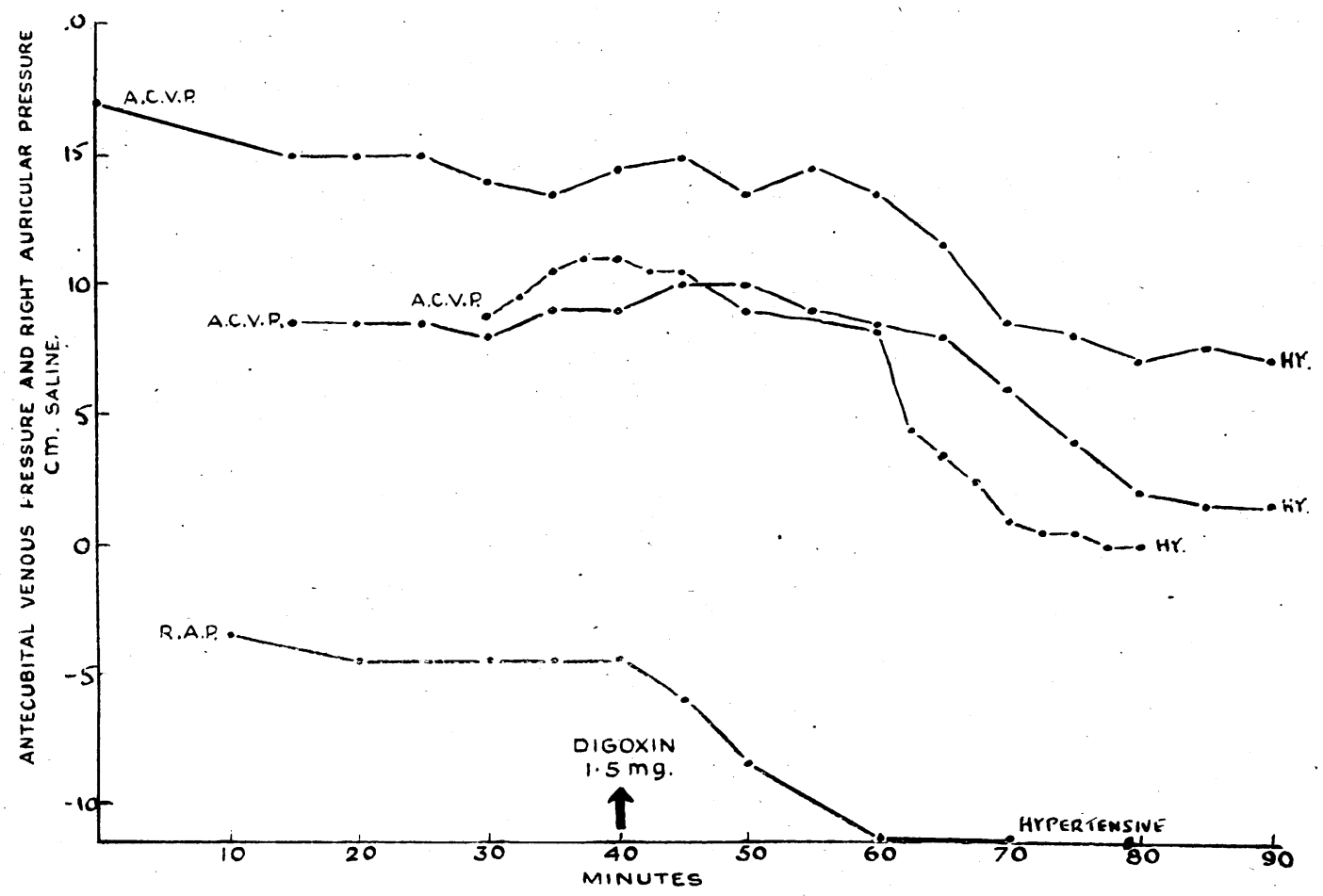

FIG. 1.-Congestive heart failure. The effect of intravenous digoxin on the venous or right auricular pressure in four cases of congestive heart failure with normal rhythm. 


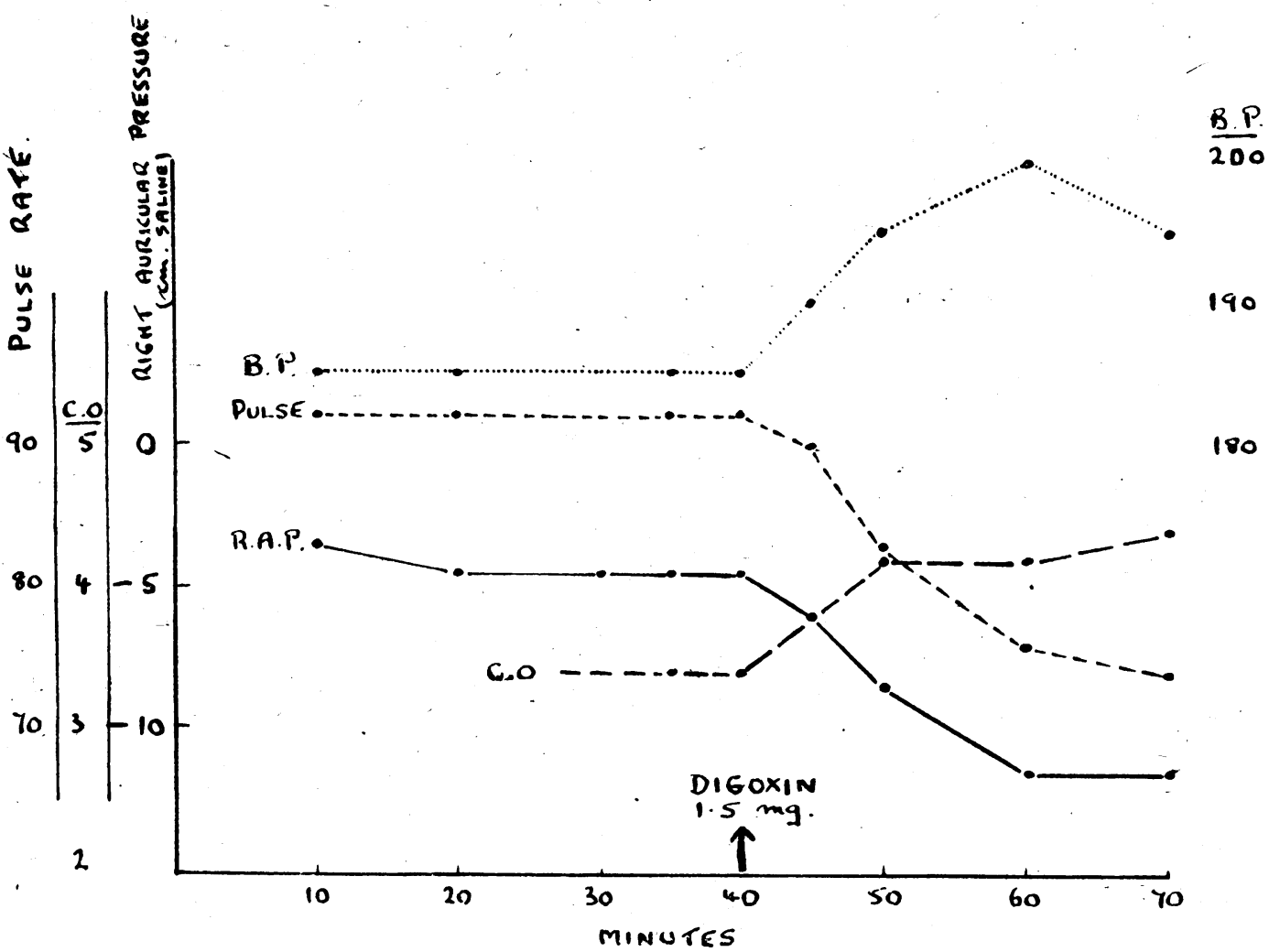

FIG. 2.-Hypertensive heart failure. The effects of intravenous digoxin on the blood pressure, pulse rate, right auricular pressure and cardiac output in a case of hypertensive heart failure. Oxygen capacity and hæmoglobin assumed normal. Oxygen consumption assumed $300 \mathrm{ml} . / \mathrm{min}$. A-V difference $87-68 \mathrm{ml}$./litre. Right ventricular pressure $+26 \mathrm{~cm}$. saline. After rest, low sodium and mersalyl for 14 days.

uncertain; this was a case in which transient œdema suddenly developed a fortnight or so after an acute upper respiratory tract infection, but the blood pressure, urine, and measured renal function remained normal. All three had a raised jugular venous pressure.

Intravenous digoxin (1.5 mg.) did not influence the right auricular pressure or cardiac output in any of them; but the blood pressure rose as usual, and the pulse rate tended to fall (Fig. 5).

Artificial Hydramia. Considerable increase in body weight, generalized œedema, and a raised jugular venous pressure were produced in three cases by means of salt, water, and desoxy-corticosterone. Intravenous digoxin $(1.5 \mathrm{mg}$.) did not effect the right auricular pressure or the cardiac output in two of them, nor the venous pressure in the third (which was not catheterized). The blood pressure rose and the pulse rate fell slightly in the case illustrated (Fig. 6, see p. 90).

Chrotic Constrictive Pericarditis. Only one case of Pick's disease was investigated, and the opportunity to catheterize a case of pericardial effusion did not arise. Intravenous digoxin $(1.5 \mathrm{mg}$.) caused a rise in blood pressure and a fall in pulse rate, but had no influence on the right auricular pressure. The cardiac output was not measured when the pulse reached its lowest level, but was not altered 10 and 40 minutes after the injection when the pulse-rate was still unchanged or had practically regained its former level respectively (Fig. 7, see p. 91).

\section{Summary OF Results}

Digoxin thus had no effect on the right auricular pressure in these twelve cases (Fig. 8). The blood 


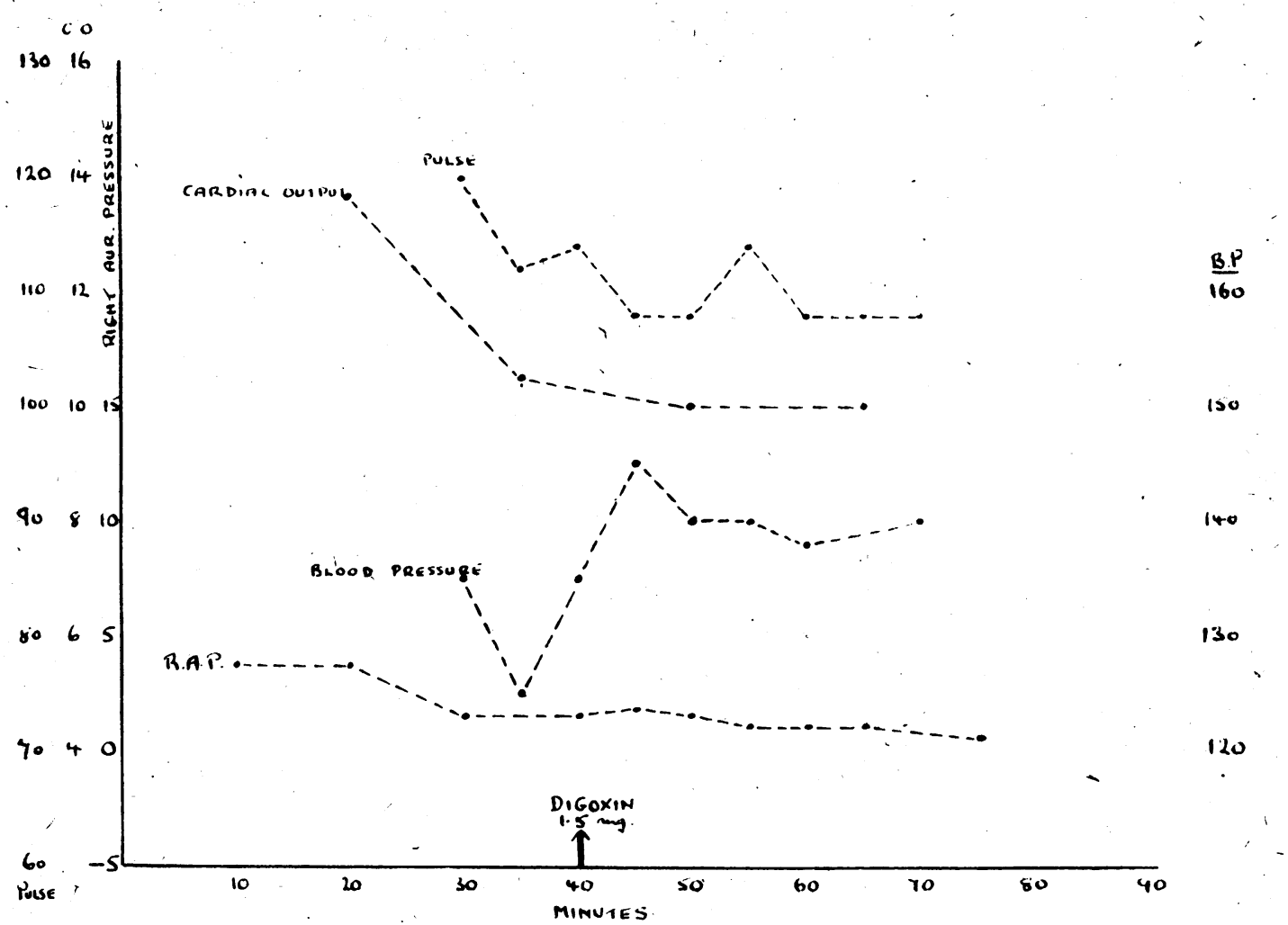

FIG. 3.-Pernicious anæmia. The effect of intravenous digoxin in a case of pernicious anæmia. The cardiac output has fallen with the pulse rate, but there is no effect on the right auricular pressure. Oxygen capacity $4 \cdot 8$ vol. per cent. Hæmoglobin 3.6 g. per $100 \mathrm{ml}$. (21 per cent Sahli). Early oxygen consumption 390, late oxygen consumption 374. R.V.P. $24 \mathrm{~cm}$. saline A-V difference 28:6-37.6 ml./litre.

pressure usually rose, and the pulse rate tended to fall; the cardiac output also fell if the pulse rate diminished sufficiently.

The cases were selected at random and represented any condition that was encountered by the authors during 1947 and 1948 in which a raised jugular venous pressure could be attributed to causes other than congestive heart failure; moreover, they were consecutive, and no such cases have been excluded.

Absence of congestive heart failure was confirmed by the behaviour of the cardiac output and by the arteriovenous oxygen difference. The former was high or normal, except in one (Case 10) complicated by nausea and vomiting; it fell with rest and slowing of the pulse, and was certainly capable of being raised considerably in some cases, if not in all. The latter was normal or less than normal, and was never increased (except in Case 10). In congestive heart failure proper the cardiac output is low, or if it is normal or raised it is not as high as it should be; in other words the circulation is incapable of meeting the demands of the body, the most consistent finding being an increased arteriovenous oxygen difference (Stead, Warren, and Brannon, 1948).

If digitalis had a primary action in lowering venous pressure it is difficult to believe that it would only influence the right auricular pressure in cases of congestive heart failure. The dose used, $1.5 \mathrm{mg}$. of digoxin intravenously, was the same as that employed by McMichael and Sharpey-Schafer (1944), was sufficient to raise the blood pressure and slow the pulse rate in most cases, and had the usual effect in heart failure. Nevertheless, it is admitted that a larger dose might possibly be required in the type of cases investigated in this paper.

If digitalis does not have a primary action in lowering venous pressure, its apparent ill effect in cases of chronic pulmonary heart failure secondary to emphysema (Howarth, McMichael, and SharpeySchafer, 1948) should be reviewed. 


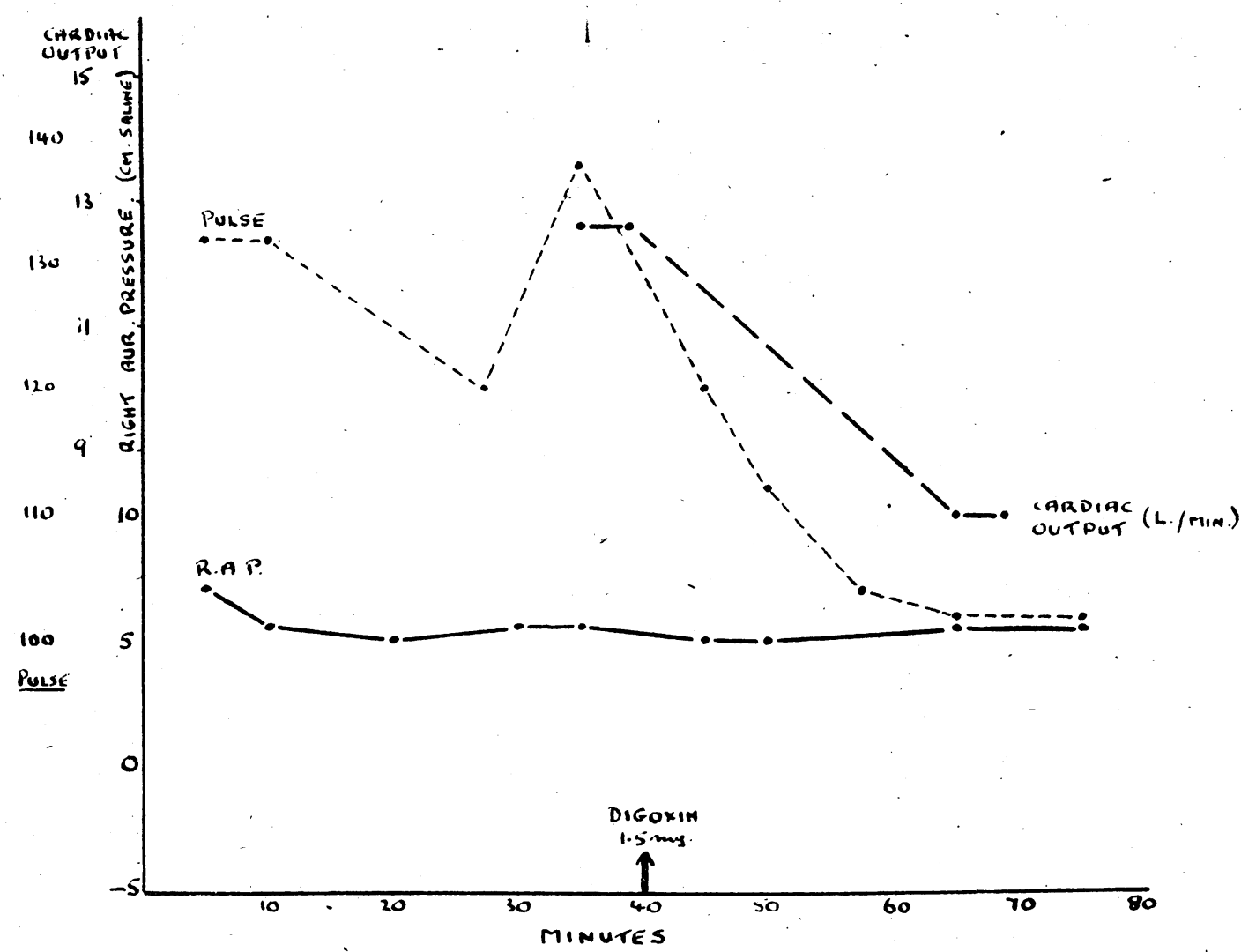

Fig. 4.-Thyrotoxicosis and anæmia. The effect of intravenous digoxin in a case of thyrotoxicosis and anæmia. The fall in cardiac output parallels the fall in pulse rate, but there is no change in the right auricular pressure. B.P. 205/100/50 throughout. Oxygen capacity 11.5 vol. per cent. Hæmoglobin $8.6 \mathrm{~g}$. per $100 \mathrm{ml}$. Oxygen consumption $380 \mathrm{ml} . / \mathrm{min}$. R.V.P. $37 \mathrm{~cm}$. saline. A-V difference $31-39$ ml./litre.

\section{SUMmaRY AND CONCLUSIONS}

The effect of digoxin on the venous pressure or right auricular pressure was investigated in four cases of classical congestive heart failure with normal rhythm and in twelve cases in which the venous pressure was raised for other reasons. These cases included anæmia, thyrotoxicosis, acute nephritis, artificial hydræmia, and chronic constrictive pericarditis. The dose of digoxin was $1.5 \mathrm{mg}$. intravenously in all instances.

In the four examples of congestive heart failure the venous pressure or right auricular pressure fell conspicuously within 30 minutes, and the cardiac output, when measured, rose.
In the twelve patients without congestive heart failure the right auricular pressure did not alter appreciably within $\mathbf{4 0}$ minutes. The cardiac output, when measured, was either unchanged or fell with the pulse rate.

A conspicuous pressor effect was demonstrated in most cases.

It is concluded that intravenous digoxin, in doses of $1.5 \mathrm{mg}$. intravenously, does not primarily lower the venous pressure, at least in the type of case described.

As a corollary, it is suggested that the effect of digoxin on the venous pressure in cases of congestive heart failure may yet depend upon its direct action on the heart, as originally believed. 


\section{REFERENCES}

Dock, W., and Tainter, M. L. (1930). J. Clin. Invest., $8,467$.

Harrison, T. R., and Leonard, B. W. (1926-7). Ibid., 3,1 .

Howarth, S., McMichael, J., and Sharpey-Schafer, E. P. (1948). Clin. Sci., 6, 187.

Katz, L. N., Mendlowitz, M., and Kaplan, H. A. (1938). Amer. Heart J., 16, 149.

Rodbard, S., Friend, M., and Rottersman, W. (1938). J. Pharm. Exper. Ther., 61, 1.
Lewis,T.(1937). Diseases of the Heart. 2nd ed., London

McKenzie, J. (1905). Brit. med. J., 1, 587.

McMichael, J., and Sharpey-Schafer, E. P. (1944a). Quart. J. Med., 13, 123.

- (1944b). Brit. Heart J., 6, 33.

Stead, E. A., Warren, J. V., and Brannon, E. S. (1948). Amer. Heart J., 35, 529.

Stewart, H. J., Deitrick, J. E., Crane, N. F., and Wheeler, C. H. (1938). Arch. intern. Med., 62, 569.

Wood, P. H. (1940). Brit. Heart J., 2, 132.

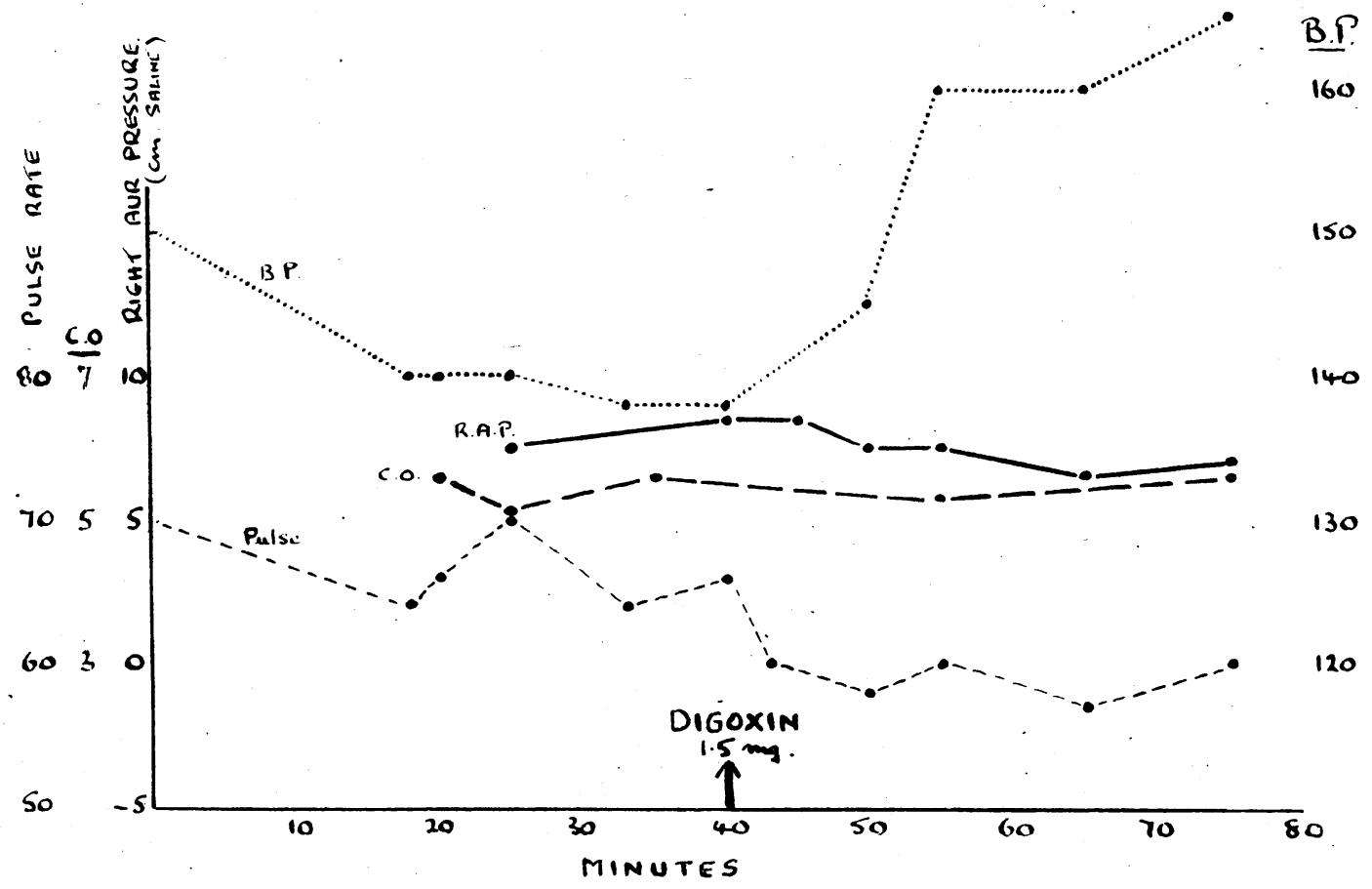

FIG. 5.-Acute nephritis. The effect of intravenous-digoxin in a case of acute nephritis. There is no significant change in cardiac output or right auricular pressure, but there is a conspicuous rise of blood pressure. Oxygen capacity 16.9 vol. per cent. Hæmoglobin 12.6 g. per $100 \mathrm{ml}$. Oxygen consumption $257 \mathrm{ml} . / \mathrm{min}$. R.V.P. $20 \mathrm{~cm}$. saline. A-V difference $46 \cdot 5-51 \cdot 5 \mathrm{ml}$./litre. 
FIG. 6.-Induced hydræmia. The effect of intravenous digoxin in a case of induced hydræmia. There is no change in the right auricular pressure. The usual pressor and slowing effects may be noted. Basal oxygen uptake $208 \mathrm{ml}$./min. Oxygen capacity $161 \mathrm{ml}$./litre. Hæmoglobin $12 \mathrm{~g}$. per $100 \mathrm{ml}$. R.V.P. 14 cm. saline. P.A.P. $24 \mathrm{~cm}$. saline. A-V difference $105-115 \mathrm{ml}$./litre. Fourteen days preparation: $\mathrm{NaCl}$. 10 g. daily. Water $10-12$ pints. DOCA $25-50 \mathrm{mg}$. Gained 11 lb. Edema+J.V.P.+2-3. at 35'. Some nausea and vomiting.

Fig. 7 and 8 . See next page. 


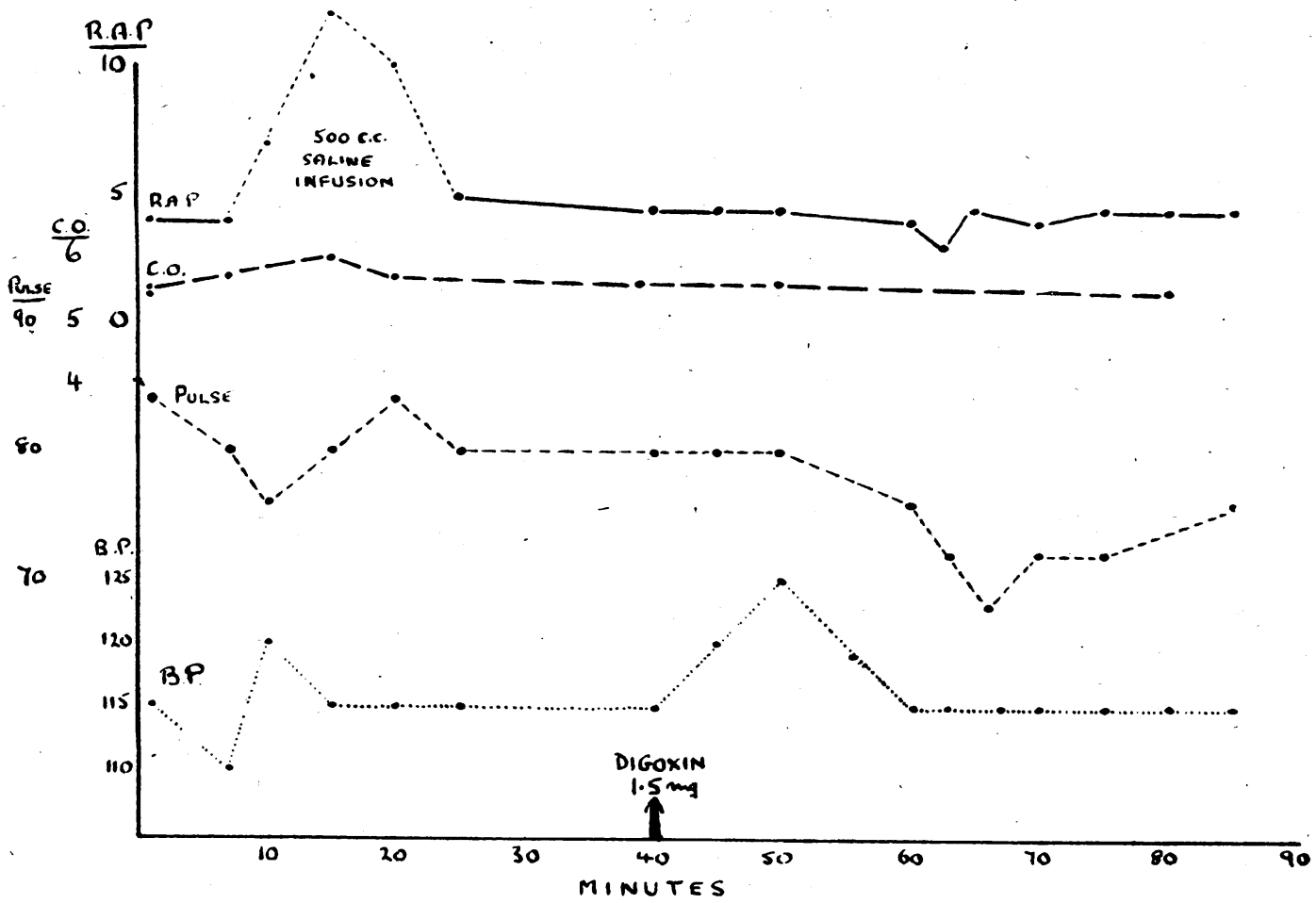

Fig. 7.-Pick's disease. The effect of intravenous digoxin in a case of Pick's disease. There is no change in the right auricular pressure. Oxygen consumption $286 \mathrm{ml} . / \mathrm{min}$. R.V.P. 10.5 cm. saline. Oxygen capacity assumed 20 vol. per cent. A-V difference $48-54 \mathrm{ml}$./litre.

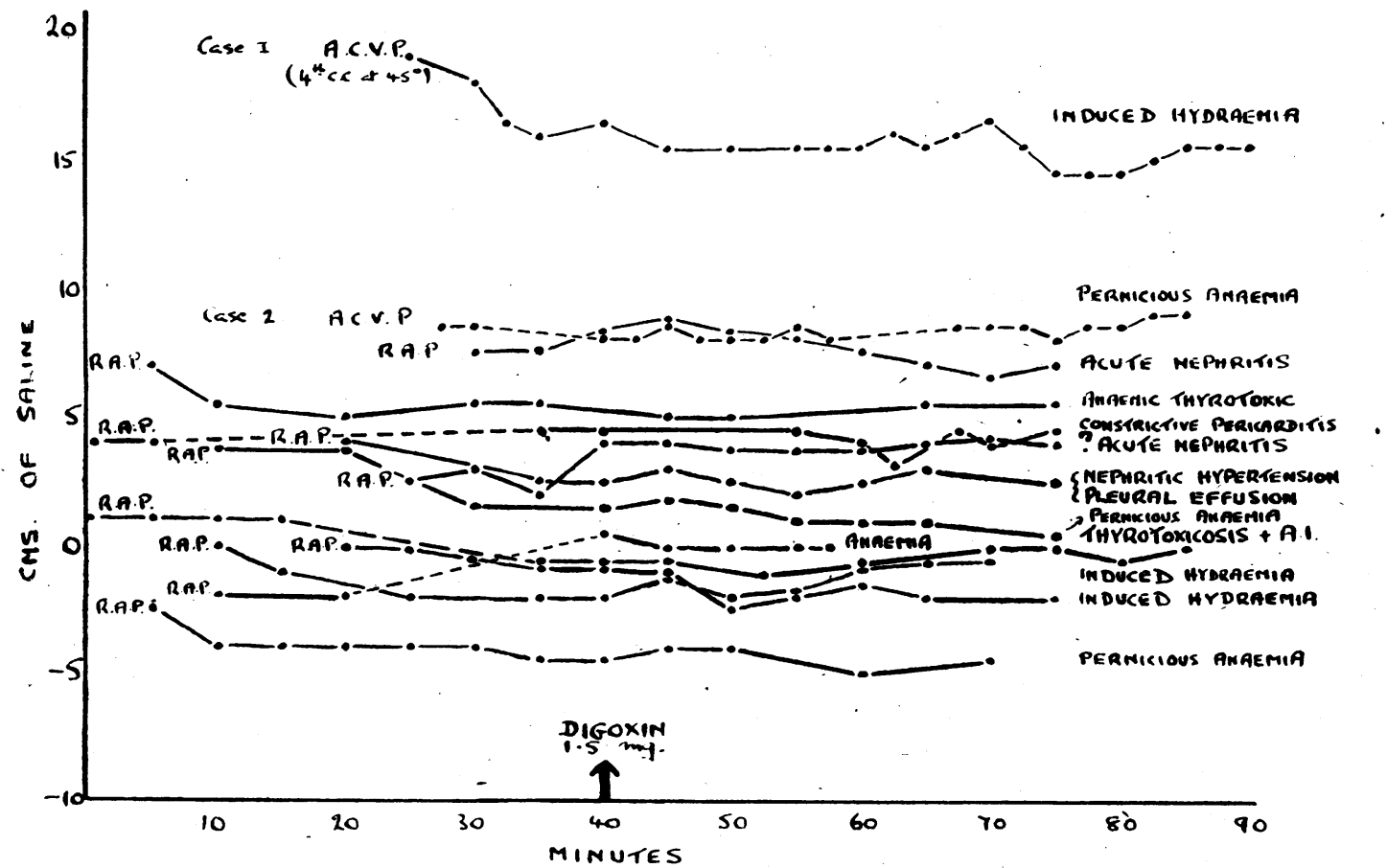

FIo. 8.-Absence of effect of digoxin on the venous pressure in cases without congestive heart failure. Superimposed charts illustrating the absence of appreciable change in the right auricular pressure as a result of digoxin in 12 cases characterized by a rise in venous pressure without heart failure. 